\title{
Dynamic Analysis and Chaos of the 4D Fractional-Order Power System
}

\author{
Fengyun Sun and Qin Li \\ School of Mathematics and Computational Science, Yantai University, Yantai 264005, China \\ Correspondence should be addressed to Fengyun Sun; mathsfy@163.com
}

Received 24 December 2013; Accepted 14 January 2014; Published 23 February 2014

Academic Editor: Xinguang Zhang

Copyright ( 2014 F. Sun and Q. Li. This is an open access article distributed under the Creative Commons Attribution License, which permits unrestricted use, distribution, and reproduction in any medium, provided the original work is properly cited.

\begin{abstract}
Now dealing with power system became the most important arts. In this paper we report the dynamic analysis of a fractional-order power system with parameter $Q_{1}$. To the best know of our knowledge, that was the first report about bifurcation analysis of the fractional order power system. So first we discuss the dynamic analysis with different fractional order and different parameters. Furthermore we will establish its numerical simulations which are provided to demonstrate the feasibility and efficacy of our analysis.
\end{abstract}

\section{Introduction}

For a long time, many researchers have been growing interest in investigating the potential use of dynamics in applications, taking power system as an example. Under normal and emergency operating conditions, power systems always can show rich nonlinear dynamic phenomena. From a mathematical point of view, differential equations can be used to describe the dynamic behavior of the power system. The power system is usually run under equilibrium conditions, but in engineering practice, the stability of the equilibrium point form sometimes changes with the range of small perturbations. After 1980s, with the development of the power system, even if a small perturbation can also cause the system to lose stability, due to the changing of some control parameters. Researchers focus on the study of the critical state of the system.

Along with the 300-year-old history of the fractional calculus, its applications to electrical engineering have received more attention. Typically, chaotic systems are still chaotic even when their differential equations become fractionalorder differential systems [1-9]. We all know there are many results on fractional-order system, but the bifurcation of fractional-order nonlinear systems has not been well studied.
Obviously there are two kinds of methods which have been used in the previous paper to solve fractional-order differential systems: the frequency-domain methods [10] and the time-domain methods [11]. Some researcher found it is sometimes invalid to research some chaotic systems who used the frequently method to investigate chaos $[12,13]$. However, we give up the first method and choice the time domain method to make the numerical simulations in this paper. The main idea was introduced by Diethelm et al. [14] and has been used by the following paper [15-17].

In this paper, we report the first investigation of a fractional-order power system using the time domain method. Recently, a simplified 4D power system was reported by Chiang et al. [18]. Its chaotic and bifurcation analysis have been investigated and got well results $[19,20]$. But to the best know of our knowledge, that was the first report about bifurcation analysis of the fractional-order system. According to the different values we will show the bifurcation diagrams of the system which chaos exists.

The paper is organized as follows. In Section 2, the numerical algorithm for the fractional-order power system is presented. In Section 3, the chaotic behavior and bifurcations of the system are studied. Finally, we summarize the results. 

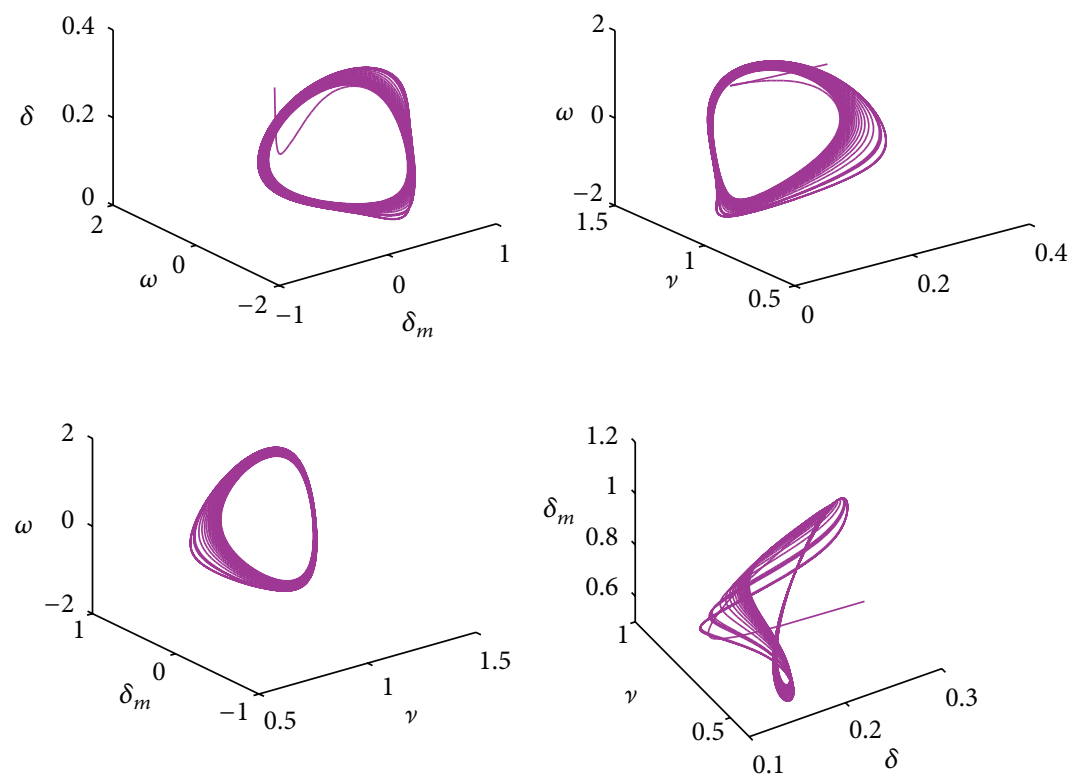

(a)

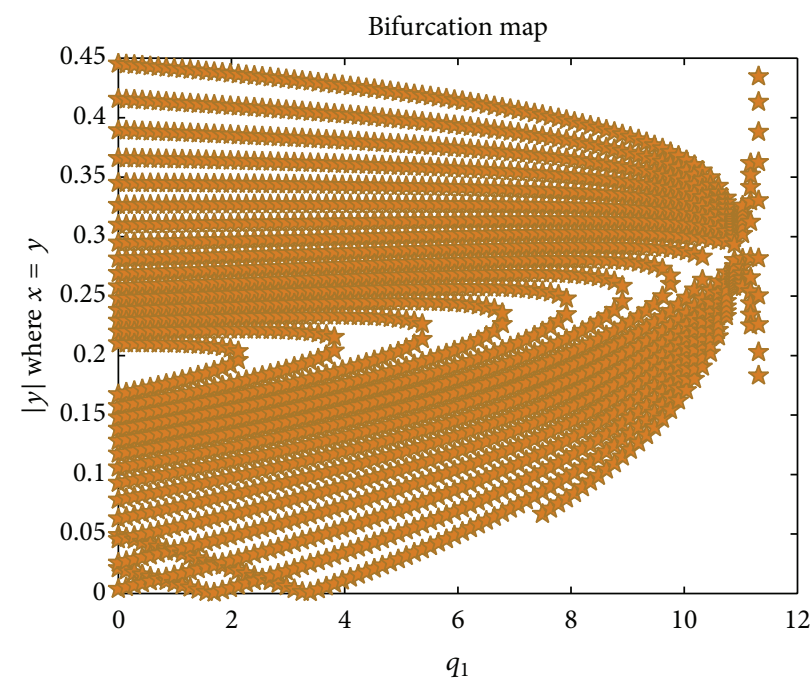

(b)

FIgURE 1: (a) The 3D trajectory in the integer order power system. (b) The related bifurcation diagram of the parameter $Q_{1}$.

\section{Numerical Algorithm for Fractional-Order Power System}

2.1. System Description [21]. In this paper we consider the following power system in [21] (see Figure 1). Here we use $Q_{1}$ as the varying parameter to derive the corresponding attractor.

Now we consider the fraction order power system by

$$
\begin{gathered}
\frac{d^{q_{1}} \delta_{m}}{d t^{q}}=\omega ; \\
\frac{d^{q_{2}} \omega}{d t^{q}}=\frac{50}{3} \nu \sin \left(\delta-\delta_{m}+0.0873\right)-\frac{1}{6} \omega+\frac{47}{25}
\end{gathered}
$$

$$
\begin{array}{rl}
\frac{d^{q_{3}} \delta}{d t^{q}}=496 & 8 \nu^{2}-\frac{50}{3} \nu \cos \left(\delta-\delta_{m}-0.0873\right) \\
& -\frac{2000}{3} v \cos (\delta-0.2094) \\
& -\frac{280}{3} v+\frac{100}{3} Q_{1}+\frac{130}{3}
\end{array}
$$$$
\frac{d^{q_{4}} v}{d t^{q}}=-78.7 v^{2}+26.2 \nu \cos \left(\delta-\delta_{m}-0.0124\right)
$$$$
+\frac{524}{5} v \cos (\delta-0.1346)+\frac{29}{2} v-5.3 Q_{1}-\frac{703}{100}
$$ 
here $\delta_{m}, \omega, \delta$, and $\nu$ are variables and $d^{q_{i}} / d t^{q_{i}}=D_{*}^{q_{i}}(i=$ $1,2,3,4)$, its order is denoted by $q=\left(q_{1}, q_{2}, q_{3}, q_{4}\right)$. When $q_{i}=1, i=1,2,3,4$, system (1) becomes the integer order power system in [21].

2.2. Fractional Derivative [22]. There are several definitions of a fractional-order differential system. In the following, we introduce the most common one of them [22]:

$$
D_{*}^{\alpha} x(t)=J^{m-\alpha} x(t)^{(m)}, \quad \text { with } \alpha>0
$$

with $m=[\alpha]$; that is, $m$ is the first integer which is not less than $\alpha, x^{m}$ is the $m$-order derivative in the usual sense, and $J^{\beta}(\beta>0)$ is the $\beta$-order Reimann-Liouville integral operator with expression

$$
J^{\beta} y(t)=\frac{1}{\Gamma(\beta)} \int_{0}^{t}(t-\tau)^{\beta-1} y(\tau) d \tau
$$

Here $\tau$ stands for Gamma function, and the operator $D_{*}^{\alpha}$ is generally called " $\alpha$-order Caputo differential operator" [22].

Next, we consider the fractional-order differential equation with related initial conditions

$$
\begin{gathered}
D_{*}^{\alpha} x(t)=f(t, x(t)), \quad 0<t<T, \\
x^{(k)}(0)=x_{0}^{(k)}, \quad k=0,1,2, \ldots n-1 .
\end{gathered}
$$

Combined with the methods [11, 14] and the above definition of fractional-order differential equation. Set $\tau=$ $T / N$, the fractional-order power system can be rewritten

$$
\begin{aligned}
&\left(\delta_{m}\right)_{n+1}=\left(\delta_{m}\right)_{0}+\frac{\tau^{q_{1}}}{\Gamma\left(q_{1}+2\right)} \\
& \times\left\{\omega_{n+1}^{p}+\sum_{j=0}^{n}\left(a_{1}\right)_{j, n+1} \omega_{j}\right\} ; \\
& \omega_{n+1}= \omega_{0}+\frac{\tau^{q_{2}}}{\Gamma\left(q_{2}+2\right)} \\
& \times\left\{\frac{50}{3} v_{n+1}^{p} \sin \left(\delta_{n+1}^{p}-\left(\delta_{m}\right)_{n+1}^{p}+0.0873\right)\right. \\
&-\frac{1}{6} \omega_{n+1}^{p}+\frac{47}{25} \\
&+\sum_{j=0}^{n}\left(a_{2}\right)_{j, n+1}\left[\frac { 5 0 } { 3 } v _ { j } \operatorname { s i n } \left(\delta_{j}-\left(\delta_{m}\right)_{j}\right.\right. \\
&\left.\left.\quad-\frac{1}{6} \omega_{j}+\frac{47}{25}\right]\right\} ;
\end{aligned}
$$

$$
\begin{aligned}
\delta_{n+1}=\delta_{0} & +\frac{\tau^{q_{3}}}{\Gamma\left(q_{3}+2\right)} \\
\times\{ & 496.8\left(v_{n+1}^{p}\right)^{2}-\frac{50}{3} v_{n+1}^{p} \\
& \times \cos \left(\delta_{n+1}^{p}-\left(\delta_{m}\right)_{n+1}^{p}-0.0873\right) \\
& -\frac{2000}{3} v_{n+1}^{p} \cos \left(\delta_{n+1}^{p}-0.2094\right)-\frac{280}{3} v_{n+1}^{p} \\
+ & \frac{100}{3} q_{1}+\frac{130}{3} \\
+ & \quad-\frac{50}{3} v_{j}\left(a_{3}\right)_{j, n+1}[ \\
& \times \cos \left(\delta_{j}-\left(\delta_{m}\right)_{j}-0.0873\right) \\
& \quad-\frac{2000}{3} v_{j} \\
& \times \cos \left(\delta_{j}-0.2094\right) \\
& \left.\left.\quad-\frac{280}{3} v_{j}+\frac{100}{3} q_{1}+\frac{130}{3}\right]\right\} ;
\end{aligned}
$$$$
v_{n+1}=v_{0}+\frac{\tau^{q_{4}}}{\Gamma\left(q_{4}+2\right)}
$$$$
\times\left\{-78.7\left(v_{n+1}^{p}\right)^{2}-26.2 v_{n+1}^{p}\right.
$$$$
\times \cos \left(\delta_{n+1}^{p}-\left(\delta_{m}\right)_{n+1}^{p}-0.0124\right)
$$$$
-\frac{524}{5} v_{n+1}^{p} \cos \left(\delta_{n+1}^{p}-0.1346\right)
$$$$
+\frac{29}{2} v_{n+1}^{p}-5.3 q_{1}-\frac{703}{100}
$$$$
+\sum_{j=0}^{n}\left(a_{4}\right)_{j, n+1}\left[-78.7\left(v_{j}\right)^{2}-26.2 v_{j}\right.
$$$$
\times \cos \left(\delta_{j}-\left(\delta_{m}\right)_{j}-0.0124\right)
$$$$
-\frac{524}{5} v_{j} \cos \left(\delta_{j}-0.1346\right)
$$$$
\left.\left.+\frac{29}{2} v_{j}-5.3 q_{1}-\frac{703}{100}\right]\right\} \text {; }
$$

in which

$$
\begin{gathered}
\left(\delta_{m}\right)_{n+1}^{p}=\left(\delta_{m}\right)_{0}+\frac{1}{\Gamma\left(q_{1}\right)} \sum_{j=0}^{n}\left(b_{1}\right)_{j, n+1} \omega_{j} ; \\
\omega_{n+1}^{p}=\omega_{0}+\frac{1}{\Gamma\left(q_{2}\right)}
\end{gathered}
$$




$$
\begin{aligned}
& \times \sum_{j=0}^{n}\left(b_{2}\right)_{j, n+1}\left[\frac{50}{3} v_{j}\right. \\
& \times \sin \left(\delta_{j}-\left(\delta_{m}\right)_{j}+0.0873\right) \\
& \left.-\frac{1}{6} \omega_{j}+\frac{47}{25}\right] \text {; } \\
& \delta_{n+1}^{p}=\delta_{0}+\frac{1}{\Gamma\left(q_{3}\right)} \\
& \times \sum_{j=0}^{n}\left(b_{3}\right)_{j, n+1}\left[496.8\left(v_{j}\right)^{2}\right. \\
& -\frac{50}{3} v_{j} \cos \left(\delta_{j}-\left(\delta_{m}\right)_{j}-0.0873\right) \\
& -\frac{2000}{3} v_{j} \cos \left(\delta_{j}-0.2094\right) \\
& \left.-\frac{280}{3} v_{j}+\frac{100}{3} q_{1}+\frac{130}{3}\right] \text {; } \\
& v_{n+1}^{p}=v_{0}+\frac{1}{\Gamma\left(q_{4}\right)} \\
& \times \sum_{j=0}^{n}\left(b_{4}\right)_{j, n+1}\left[-78.7\left(v_{j}\right)^{2}-26.2 v_{j}\right. \\
& \times \cos \left(\delta_{j}-\left(\delta_{m}\right)_{j}-0.0124\right) \\
& -\frac{524}{5} v_{j} \cos \left(\delta_{j}-0.1346\right) \\
& \left.+\frac{29}{2} v_{j}-5.3 q_{1}-\frac{703}{100}\right] \text {; } \\
& \left(a_{1}\right)_{j, n+1}=\left\{\begin{array}{cl}
n^{q_{1}}-\left(n-q_{1}\right)(n+1)^{q_{1}}, & j=0, \\
(n-j+2)^{q_{1}+1}+(n-j)^{q_{1}+1} & \\
-2(n-j+1)^{q_{1}+1}, & 0 \leq j \leq n,
\end{array}\right. \\
& \left(a_{2}\right)_{j, n+1}=\left\{\begin{array}{cl}
n^{q_{2}}-\left(n-q_{2}\right)(n+1)^{q_{2}}, & j=0, \\
(n-j+2)^{q_{2}+1}+(n-j)^{q_{2}+1} & \\
-2(n-j+1)^{q_{2}+1}, & 0 \leq j \leq n,
\end{array}\right. \\
& \left(a_{3}\right)_{j, n+1}=\left\{\begin{array}{cl}
n^{q_{3}}-\left(n-q_{3}\right)(n+1)^{q_{3}}, & j=0, \\
(n-j+2)^{q_{3}+1}+(n-j)^{q_{3}+1} & \\
-2(n-j+1)^{q_{3}+1}, & 0 \leq j \leq n,
\end{array}\right. \\
& \left(a_{4}\right)_{j, n+1}=\left\{\begin{array}{cl}
n^{q_{4}}-\left(n-q_{4}\right)(n+1)^{q_{4}}, & j=0, \\
(n-j+2)^{q_{4}+1}+(n-j)^{q_{4}+1} & \\
-2(n-j+1)^{q_{4}+1}, & 0 \leq j \leq n,
\end{array}\right. \\
& \left(b_{1}\right)_{j, n+1}=\frac{\tau^{q_{1}}}{q_{1}}\left((n-j+1)^{q_{1}}-(n-j)^{q_{1}}\right), \quad 0 \leq j \leq n, \\
& \left(b_{2}\right)_{j, n+1}=\frac{\tau^{q_{2}}}{q_{2}}\left((n-j+1)^{q_{2}}-(n-j)^{q_{2}}\right), \quad 0 \leq j \leq n, \\
& \left(b_{3}\right)_{j, n+1}=\frac{\tau^{q_{3}}}{q_{3}}\left((n-j+1)^{q_{3}}-(n-j)^{q_{3}}\right), \quad 0 \leq j \leq n, \\
& \left(b_{4}\right)_{j, n+1}=\frac{\tau^{q_{4}}}{q_{4}}\left((n-j+1)^{q_{4}}-(n-j)^{q_{4}}\right), \quad 0 \leq j \leq n .
\end{aligned}
$$




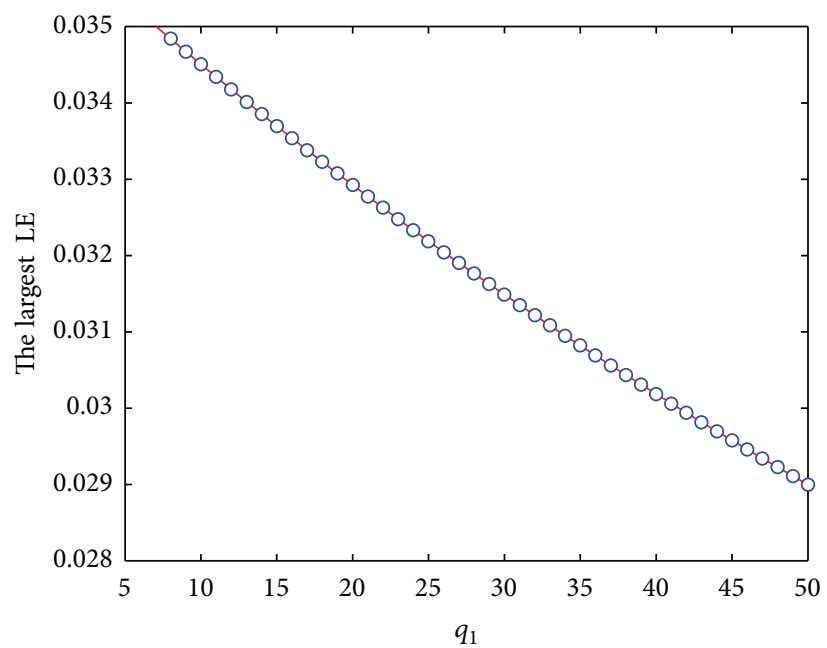

FIGURE 2: The largest Lyapunov exponent diagram.
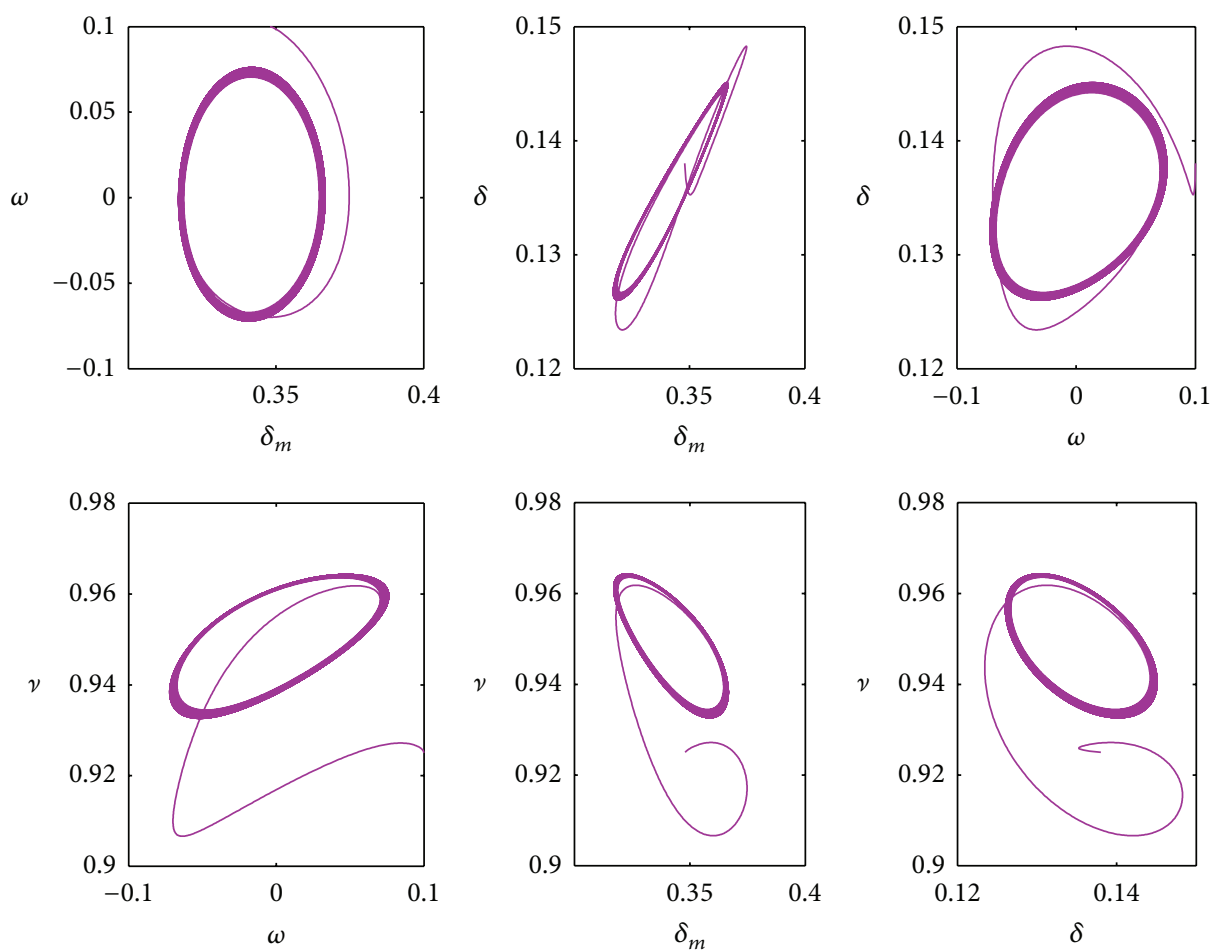

FIgURE 3: The 2D trajectory in the fractional-order power system with $q_{i}=0.99, i=1,2,3,4$.

$q_{4} \in(0.9,0.99)$ with a varied step size equal to 0.01 . The related Largest Lyapunov exponent is shown in Figure 6.

\section{Conclusions}

Through the above discussion, we successfully have numerically studied the existence of the bifurcations type of the fractional order power system with the difference orders. According to the different initial conditions and fractional order, the largest Lyapunov exponent values and the bifurcation maps are given to verify the rationality of the analysis. Of course, the next work on this topic should include the depth study in chaos control and synchronization.

\section{Conflict of Interests}

The authors declare that there is no conflict of interests regarding the publication of this paper. 

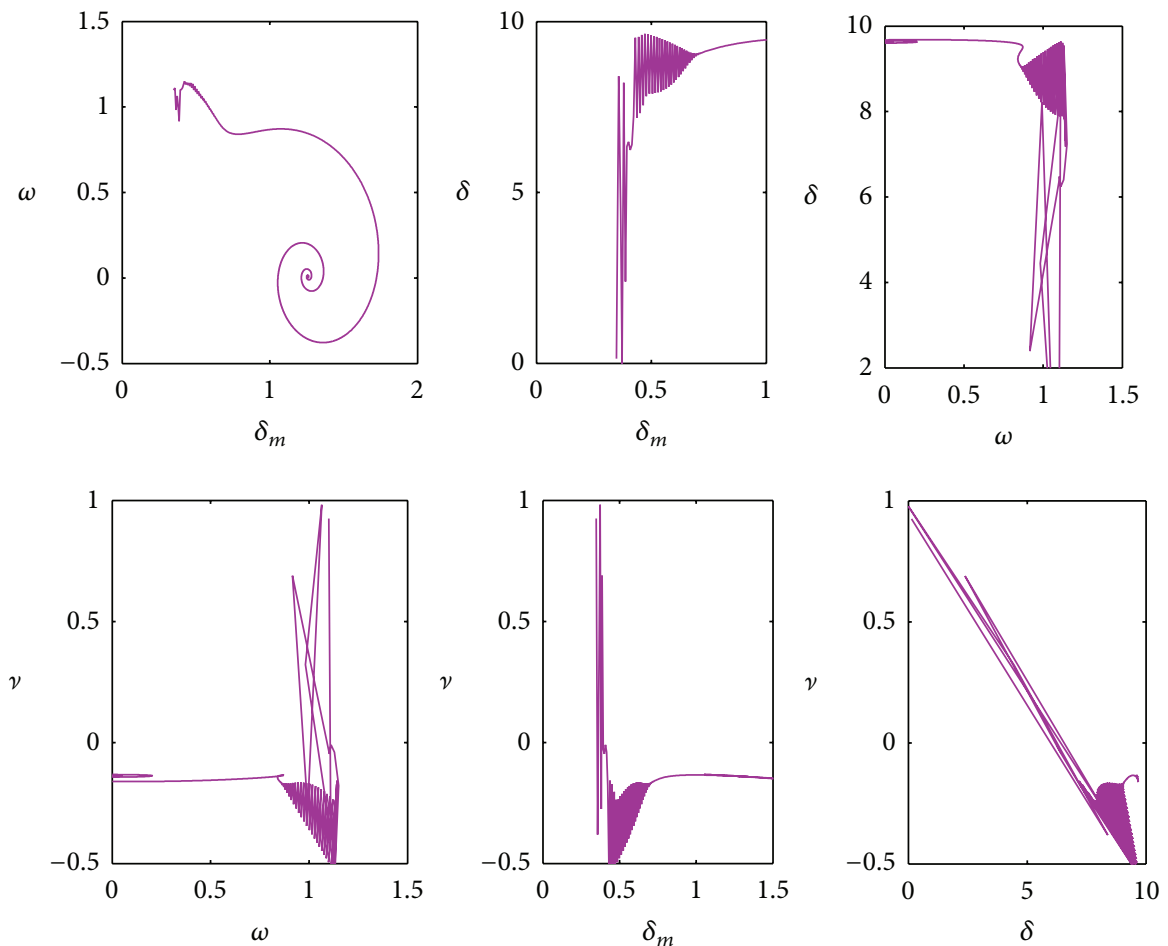

(a)
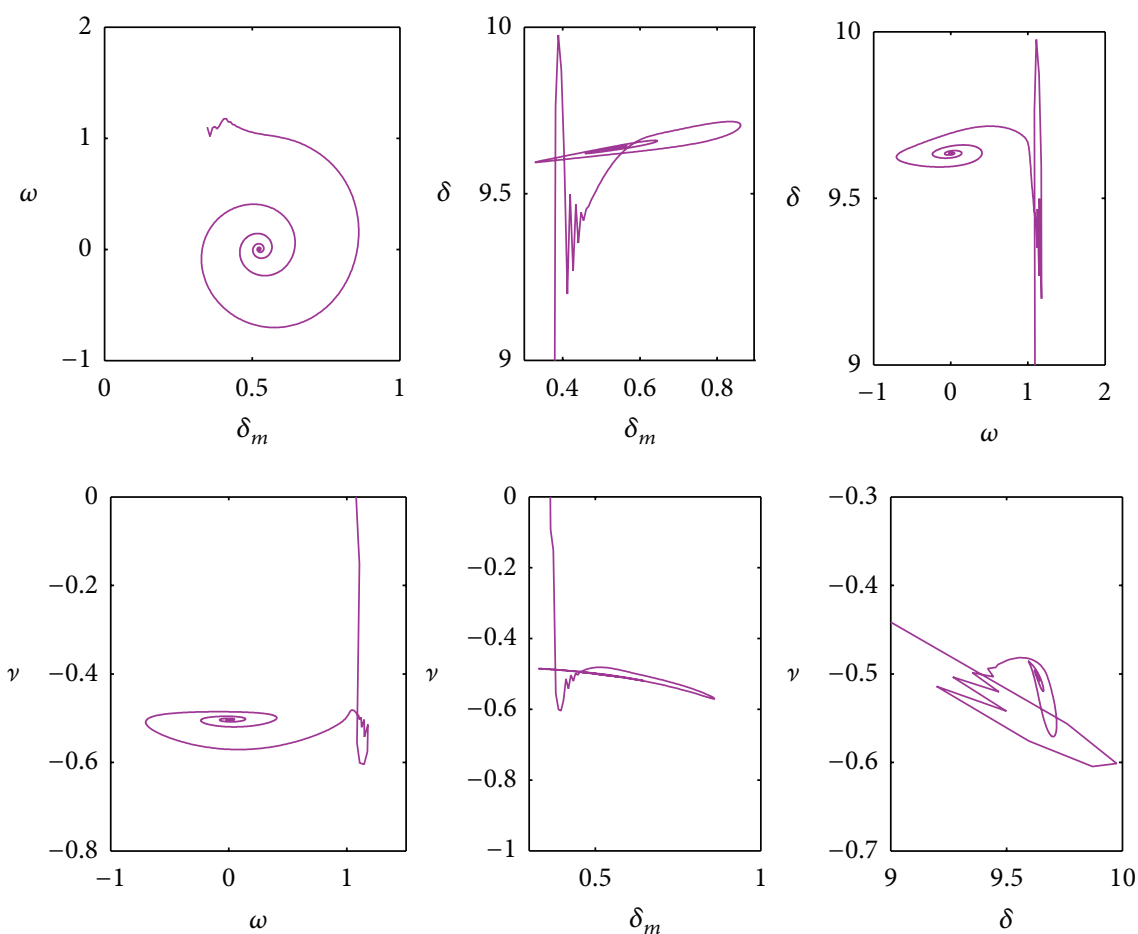

(b)

FIgURE 4: The 2D trajectory in the fractional-order power system with $q_{i}=0.9, i=1,2,3,4$. (a) $Q_{1}=1$; (b) $Q_{1}=5.9$. 


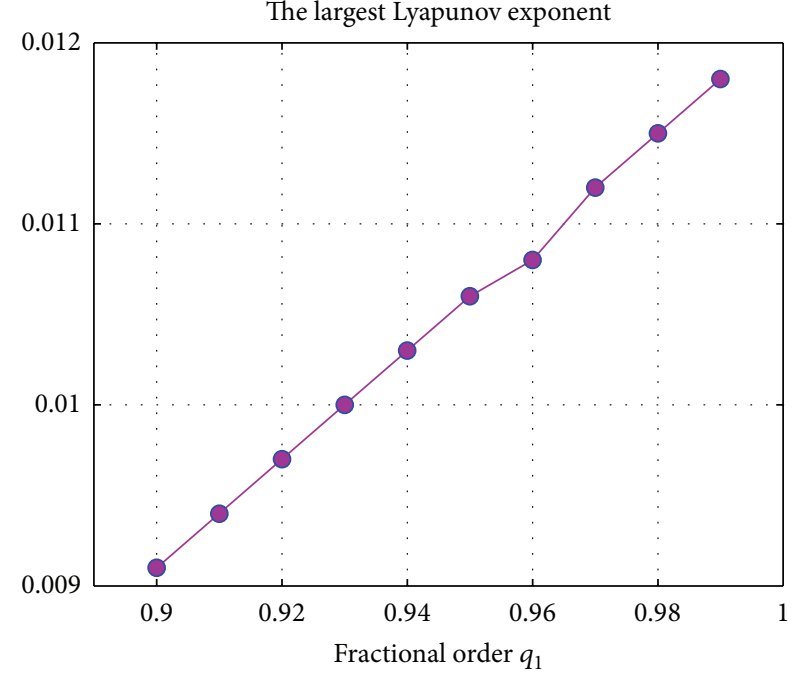

(a)

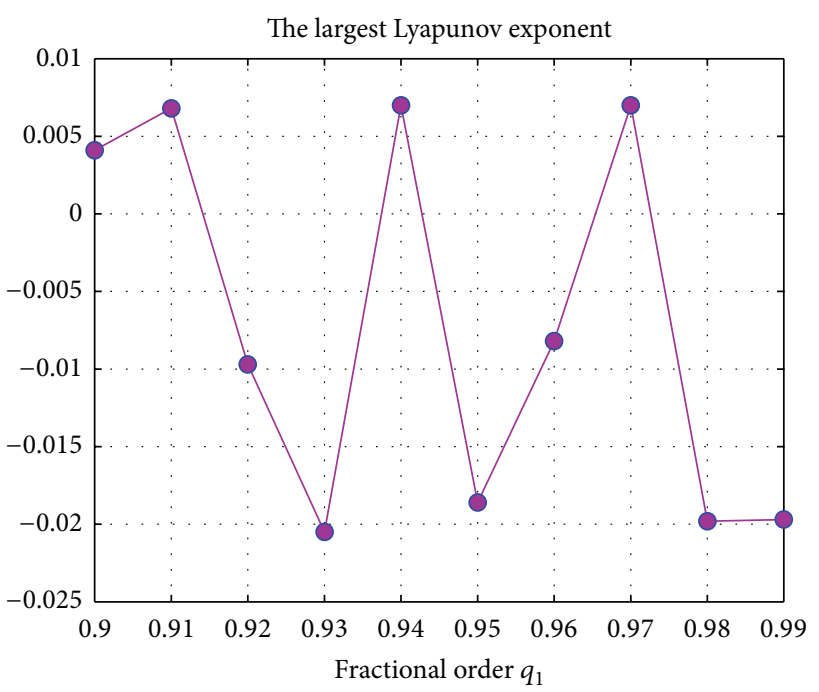

(b)

FIGURE 5: The Largest Lyapunov Exponent of the fractional-order power system; (a) $q_{2}=q_{3}=q_{4}=1, q_{1}=0.99$, and (b) $q_{1}=q_{3}=q_{4}=1$, $q_{2}=0.99$.

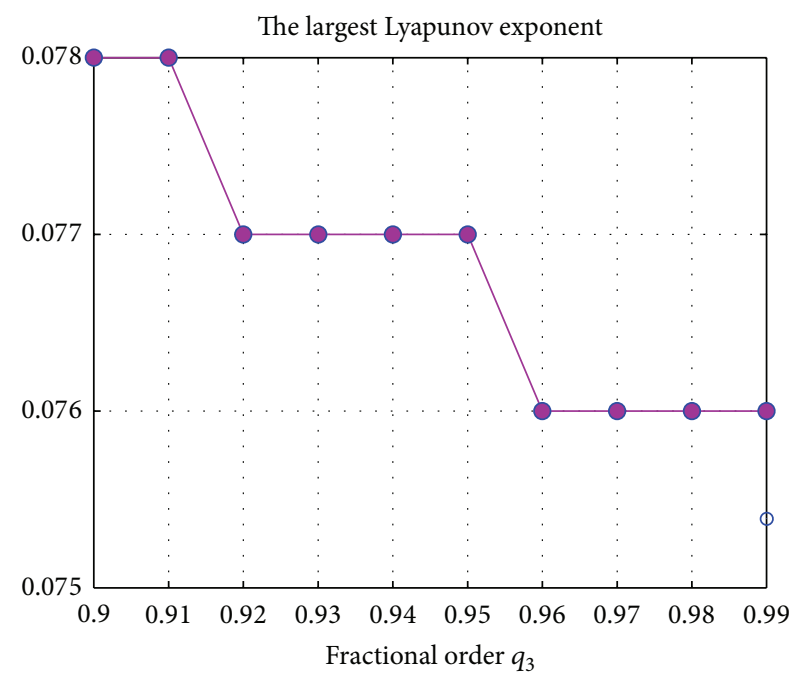

(a)

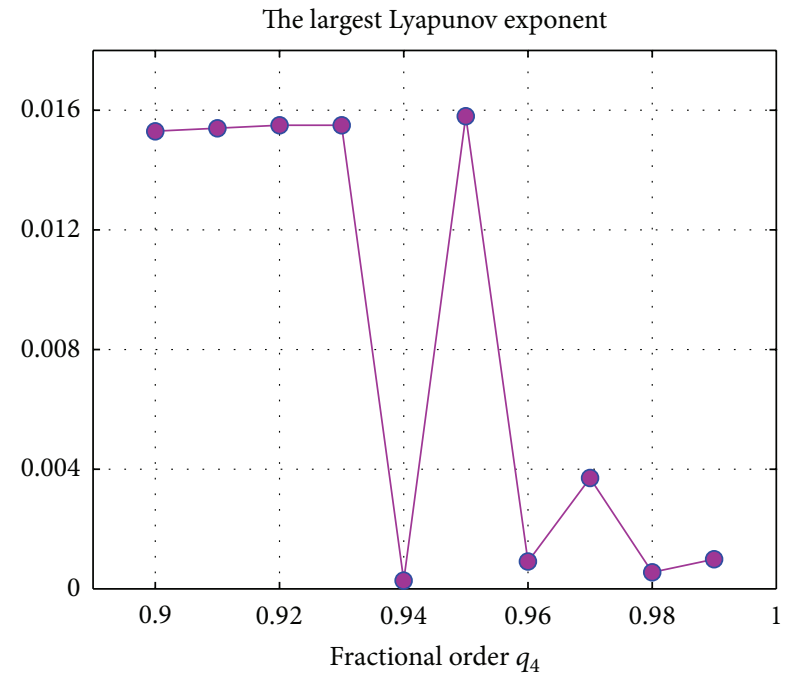

(b)

Figure 6: The Largest Lyapunov Exponent of the fractional-order power system; (a) $q_{2}=q_{1}=q_{4}=1, q_{3}=0.99$, and (b) $q_{2}=q_{3}=q_{1}=1$, $q_{4}=0.99$.

\section{Acknowledgment}

The present work was partially supported by the National Natural Science Foundation of China under Grant no. 61273128.

\section{References}

[1] P. Arena, R. Caponetto, L. Fortuna, and D. Porto, "Chaos in a fractional order duffing system," in Proceedings of the ECCTD, pp. 1259-1262, Budapest, Hungary, 1997.

[2] Z.-M. Ge and C.-Y. Ou, "Chaos in a fractional order modified Duffing system," Chaos, Solitons and Fractals, vol. 34, no. 2, pp. 262-291, 2007.
[3] W. Ahmad, R. El-khazali, and A. S. Elwakil, "Fractional-order Wien-bridge oscillator," Electronics Letters, vol. 37, no. 18, pp. 1110-1112, 2001.

[4] W. M. Ahmad and J. C. Sprott, "Chaos in fractional-order autonomous nonlinear systems," Chaos, Solitons and Fractals, vol. 16, no. 2, pp. 339-351, 2003.

[5] W. M. Ahmad and A. M. Harb, "On nonlinear control design for autonomous chaotic systems of integer and fractional orders," Chaos, Solitons and Fractals, vol. 18, no. 4, pp. 693-701, 2003.

[6] X. Zhang, L. Liu, and Y. Wu, "The uniqueness of positive solution for a singular fractional differential system involving derivatives," Communications in Nonlinear Science and Numerical Simulation, vol. 18, no. 6, pp. 1400-1409, 2013. 
[7] X. Zhang, L. Liu, and Y. Wu, "Multiple positive solutions of a singular fractional differential equation with negatively perturbed term," Mathematical and Computer Modelling, vol. 55, no. 3-4, pp. 1263-1274, 2012.

[8] X. Zhang, L. Liu, and Y. Wu, "The eigenvalue problem for a singular higher order fractional differential equation involving fractional derivatives," Applied Mathematics and Computation, vol. 218, no. 17, pp. 8526-8536, 2012.

[9] X. Zhang, L. Liu, and Y. Wu, "Existence results for multiple positive solutions of nonlinear higher order perturbed fractional differential equations with derivatives," Applied Mathematics and Computation, vol. 219, no. 4, pp. 1420-1433, 2012.

[10] H. H. Sun, A. A. Abdelwahab, and B. Onaral, "Linear approximation of transfer function with a pole of fractional power," IEEE Transactions on Automatic Control, vol. 29, no. 5, pp. 441444, 1984.

[11] K. Diethelm and N. J. Ford, "Analysis of fractional differential equations," Journal of Mathematical Analysis and Applications, vol. 265, no. 2, pp. 229-248, 2002.

[12] M. S. Tavazoei and M. Haeri, "Unreliability of frequencydomain approximation in recognising chaos in fractional-order systems," IET Signal Processing, vol. 1, no. 4, pp. 171-181, 2007.

[13] M. S. Tavazoei and M. Haeri, "Limitations of frequency domain approximation for detecting chaos in fractional order systems," Nonlinear Analysis: Theory, Methods \& Applications, vol. 69, no. 4, pp. 1299-1320, 2008.

[14] K. Diethelm, N. J. Ford, and A. D. Freed, "A predictor-corrector approach for the numerical solution of fractional differential equations," Nonlinear Dynamics, vol. 29, no. 1-4, pp. 3-22, 2002.

[15] C. Li and G. Peng, "Chaos in Chen's system with a fractional order," Chaos, Solitons \& Fractals, vol. 22, no. 2, pp. 443-450, 2004.

[16] M. S. Tavazoei and M. Haeri, "Chaotic attractors in incommensurate fractional order systems," Physica D, vol. 237, no. 20, pp. 2628-2637, 2008.

[17] K. Sun, X. Wang, and J. C. Sprott, "Bifurcations and chaos in fractional-order simplified Lorenz system," International Journal of Bifurcation and Chaos in Applied Sciences and Engineering, vol. 20, no. 4, pp. 1209-1219, 2010.

[18] I.-D. Chiang, C.-W. Liu, P. P. Varaiya, F. F. Wu, and M. G. Lauby, "Chaos in a simple power system," IEEE Transactions on Power Systems, vol. 8, no. 4, pp. 1407-1409, 1993.

[19] Z. Jing, D. Xu, Y. Chang, and L. Chen, "Bifurcations, chaos, and system collapse in a three node power system," International Journal of Electrical Power and Energy System, vol. 25, no. 6, pp. 443-461, 2003.

[20] S. Grillo, S. Massucco, A. Morini, A. Pitto, and F. Silvestre, "Bifurcation analysis and Chaos detection in power systems," in Proceedings of the 43rd International Universities Power Engineering Conference (UPECn '08), pp. 1-6, September 2008.

[21] H.-D. Chiang, I. Dobson, R. J. Thomas, J. S. Thorp, and L. FekihAhmed, "On voltage collapse in electric power systems," IEEE Transactions on Power Systems, vol. 5, no. 2, pp. 601-611, 1990.

[22] M. Caputo, "Linear models of dissipation whose $Q$ is almost frequency Independent-II.," Geophysical Journal of the Royal Astronomical Society, vol. 13, pp. 529-539, 1967. 


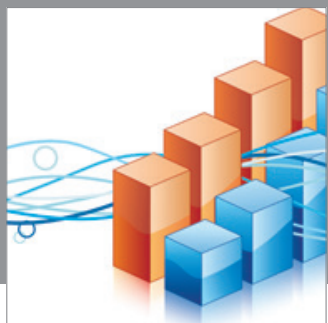

Advances in

Operations Research

mansans

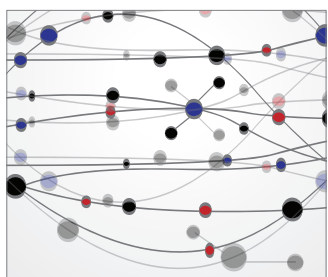

The Scientific World Journal
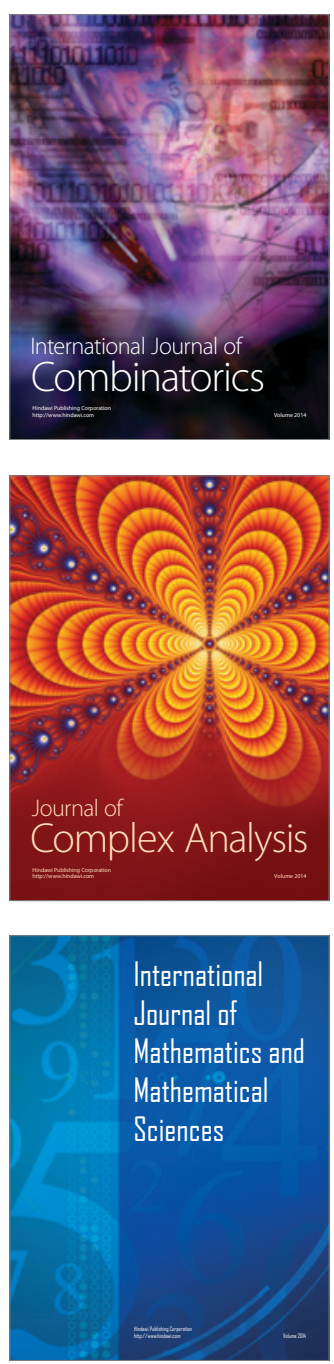
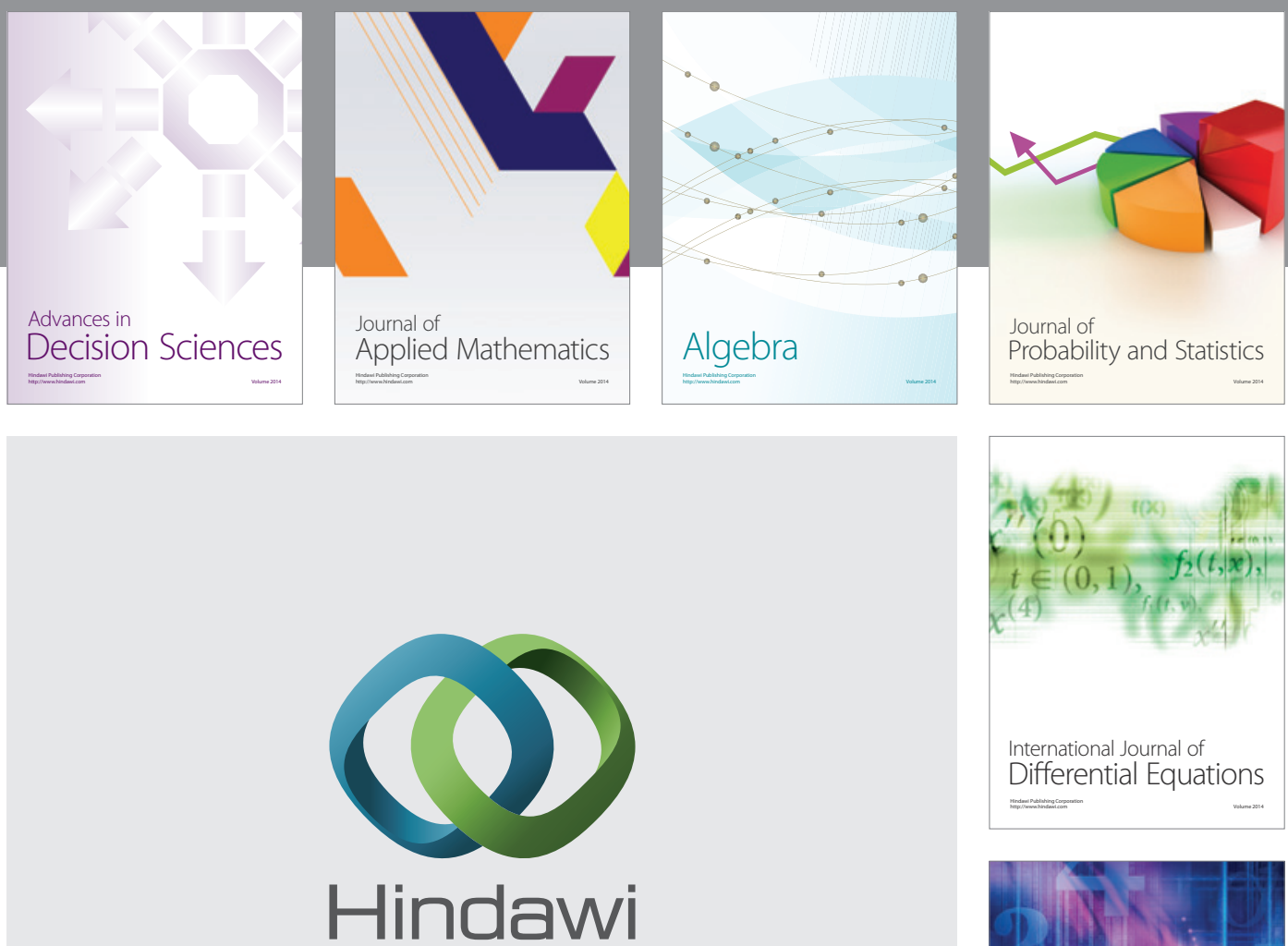

Submit your manuscripts at http://www.hindawi.com
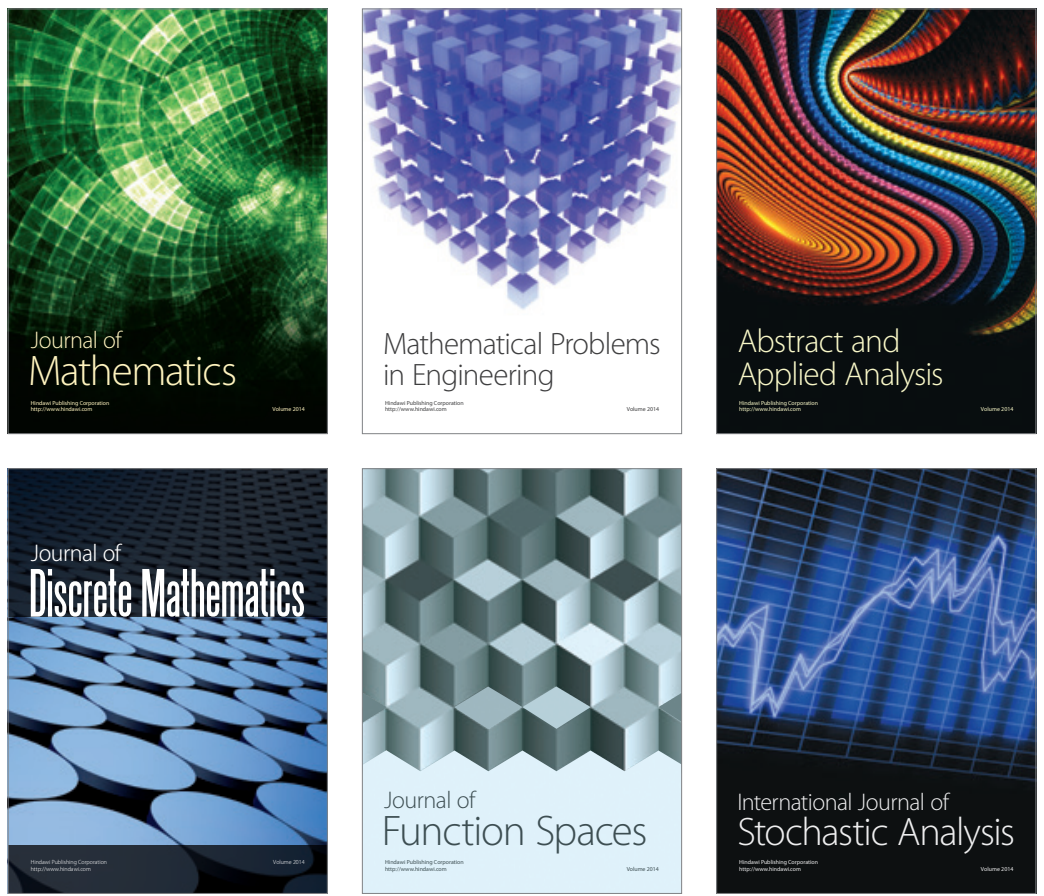

Journal of

Function Spaces

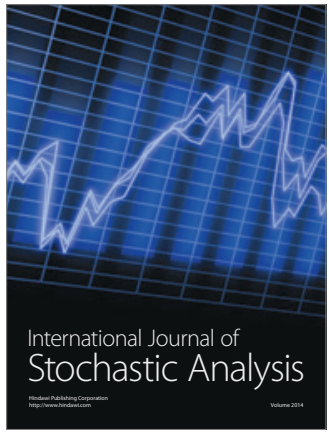

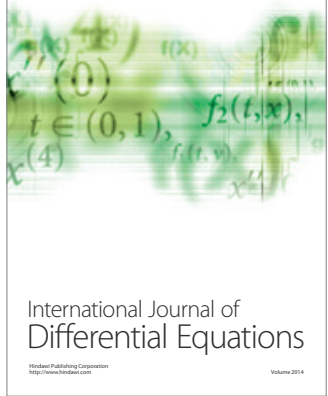
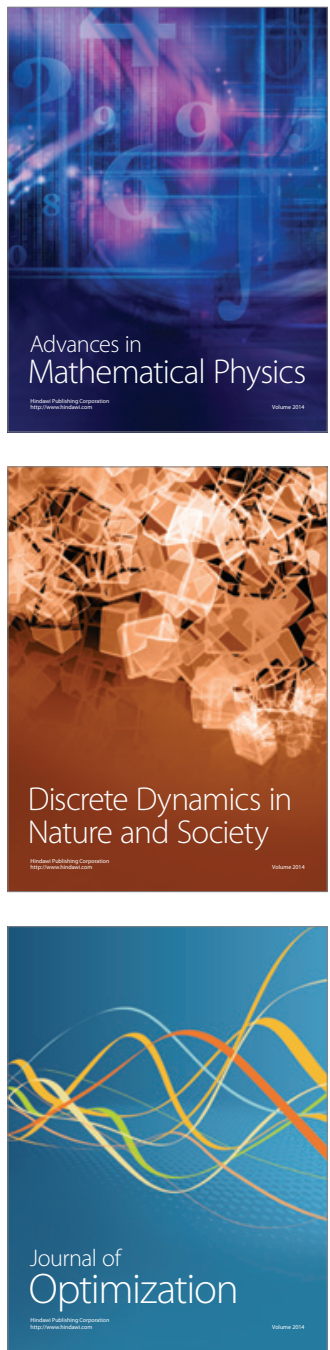